\title{
MICRO SHEAR BOND STRENGTH OF RESIN COMPOSITE TO TOOTH SUBSTRATES TREATED WITH ACID ETCHING OR CONDITIONED BY LASER: AN IN VITRO STUDY
}

\author{
Nour Eldin Ibrahim Amin Ibrahim*, Amira Farid El Zoghby** and Asmaa Youssif Harhash ${ }^{* * *}$
}

\begin{abstract}
This study was performed to evaluate the micro shear bond strength of resin composite bonded to enamel and dentin pretreated with acid etchant or Er,Cr:Ysgg. M \& M: 66 premolars were selected.Buccal and lingual surfaces were flattened.Teeth were randomly divided into two main groups according to etching methods (A); group (A1) etching by an Er, Cr: YSGG laser and (A2) etching by phosphoric acid. then each group was subdivided into two subgroups according to tooth substrate tested (S1) was for enamel, while (S2) was for dentin. Each subgroup was divided into three classes 11 specimens each according to storage time (T); stored for 1 day (T1), stored for 7 days (T2) and stored for 30 days (T3). Teeth were restored for microshear bond strength testing using universal testing machine; load was applied till specimen's fail. Results: both laser-etched enamel and dentin showed lowest microshear bond strength mean compared to acid-etched one. Conclusion: Etching with Er,Cr: YSGG laser impair the micro shear bond strength of resin composite to enamel and dentin and does not constitute an alternative to its acid etching.
\end{abstract}

\section{INTRODUCTION}

With the current trend toward esthetic dentistry, resin composites have added a whole new dimension. Its clinical performance has improved with the development of more wear-resistant formulations; newer generations of dentin bonding agents; and improved light curing and surface-sealing systems.
Erbium (Er.) lasers were introduced into dentistry specifically as an alternative to traditional mechanical instrumentation for the preparation of tooth structure ${ }^{[1]}$. These lasers emit energy in the wavelength range of 2.6 and $3 \mu \mathrm{m}$. This range coincides with the strongest absorption peak of water, an important component of dental hard tissues ${ }^{[2]}$. The sudden evaporation of bound

\footnotetext{
* Demonstrator, Operative \& Esthetics Department, Faculty of Oral \& Dental Medicine British University, Cairo, Egypt, ** Professor of Operative Dentistry, Faculty of Oral and Dental Medicine, Cairo University

*** Assistant Professor of Operative Dentistry, Faculty of Oral and Dental Medicine, Egyptian Russian University
} 
water ( $2-4 \%$ by weight in enamel) causes microexplosions that blast away tiny particles of the tooth ${ }^{[2]}$. In addition to the selective removal of carious enamel and dentin, the advantages of using lasers for hard tissue preparation include bactericidal effects and less noise, vibration, and discomfort for the patient than a rotary handpiece . A member of the Er laser family, the Er,Cr:YSGG pulsed laser used with an air-water spray may be used to prepare enamel, dentin, cementum, and bone efficiently and cleanly without leaving a smear layer ${ }^{[1]}$.

\section{MATERIALS AND METHODS}

Non-carious 66 sound human premolars were selected to prepare 132 specimens for this study. Buccal surfaces were flattened and were ground under copious water coolant to obtain a flat enamel surface while the lingual surfaces were ground to obtain a uniform flat surface of superficial dentin. Subsequently, the surfaces were polished with 240 grit, 400 grit and 600 grit sandpaper disks to standardize the smear Layer. Prepared specimens were randomly divided into two main groups, 66 specimens each, according to etching methods (A); group (A1) etching by an Er, Cr: YSGG laser system (Waterlase MD, Biolase); the parameters for enamel specimens were: $4 \mathrm{~W} 60 \%$ air, $80 \%$ water ${ }^{[3]}$ and 1.25 W $60 \%$ air, 70\% water for dentin specimens ${ }^{[4]}$ and (A2) etching by phosphoric acid using Scotchbond Universal Etchant. Each group was further divided into two subgroups 33 specimens each according to tooth substrate tested (S); where (S1) was for enamel, while (S2) was for dentin. Each subgroup was divided into three classes 11 specimens each according to storage time (T); stored for 1 day (T1), stored for 7 days (T2) and stored for 30 days (T3). The adhesive was applied on the substrate and cured then a plastic tube (Tygon tube), $0.7 \mathrm{~mm}$ in diameter and $1 \mathrm{~mm}$ in length was held securely and immobilized using cotton pliers on the indicated substrate. Then resin composite ( $\mathrm{Z} 350 \mathrm{XT}$ ) was packed into the tube and cured. Microshear bond strength test was conducted using universal testing machine at crosshead speed of $0.5 \mathrm{~mm} / \mathrm{min}$ till specimens fail, bond strength was calculated in MPs.

\section{RESULTS}

Data were presented as means and standard deviation (SD) values. Microshear bond strength (MPa) showed parametric distribution so; two-way ANOVA was used to study the effect of different treatments and time on mean Microshear bond strength (MPa) for Enamel and Dentine Substrates. Tukey's post-hoc test was used for pairwise comparison between the means when ANOVA test is significant. One-Way ANOVA was used to compare between variables and their interactions and different follow-up periods within each treatment for mean Microshear bond strength (MPa). Independent t-test was used to compare between different treatments within each time on mean Microshear bond strength (MPa).

The results are shown in (figure 1 and table 1), two way-ANOVA showed that laser-etched enamel showed the lowest significant microshear bond strength mean compared to acid-etched enamel. On the other hand, laser-etched dentin showed the lowest insignificant mean compared to acid etching treatment. It was also found that time exhibited an insignificant effect on mean microshear (MPa) on both substrates. 
TABLE (1) Mean and Slandered deviation (SD) of $\mu$-Shear Bond Strength (MPa) for the Enamel and Dentin substrates for different tested groups.

\begin{tabular}{|c|c|c|c|c|c|}
\hline \multirow{2}{*}{} & \multicolumn{2}{|c|}{$\begin{array}{c}\text { MicroShear (MPa) } \\
\text { (Enamel) }\end{array}$} & \multicolumn{2}{c|}{$\begin{array}{c}\text { MicroShear (MPa) } \\
\text { (Dentin) }\end{array}$} & p-value \\
\cline { 2 - 6 } & Mean & SD & Mean & SD & \\
\hline Laser treatment + 30 Days & 11.41 & 3.06 & 8.88 & 2.39 & $0.049 *$ \\
\hline Laser treatment + 7 Days & 11.80 & 3.29 & 9.14 & 3.09 & $0.087 \mathrm{NS}$ \\
\hline Laser treatment + 1 Days & 12.31 & 3.24 & 9.55 & 2.42 & $0.059 \mathrm{NS}$ \\
\hline Laser treatment + 30 Days & 19.55 & 2.99 & 10.33 & 2089 & $\leq 0.001 *$ \\
\hline Laser treatment + 7 Days & 20.57 & 5012 & 10.52 & 2.88 & $\leq 0.001 *$ \\
\hline Laser treatment + 1 Days & 22.18 & 5.33 & 11.01 & 2.89 & $\leq 0.001 *$ \\
\hline
\end{tabular}

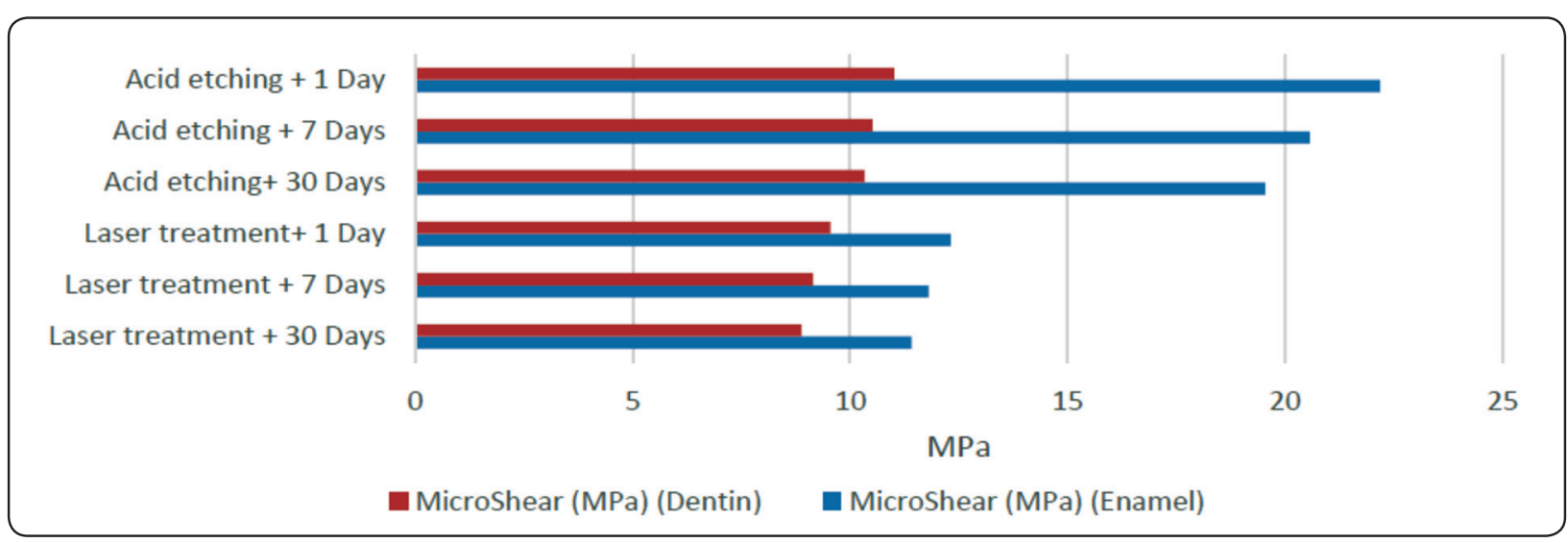

Fig. (1) Histogram showing the mean $\mu$-Shear Bond Strength (MPa) for the Enamel and Dentin substrates for different tested groups.

\section{DISCUSSION}

The advantage of an Erbium laser was selected as an intervention for this study as it is a newly Innovated laser that it is well absorbed by water and dental hard tissue. Although dentin contains a high proportion of water, the depth is shallow for laser transmission ${ }^{[5]}$. The strong absorption of water reduces the level of heat during tooth preparation. As water absorbs laser radiation better than dental hard tissue, it reduces the increasing temperature of the tissue during the preparation. Water reaches the boiling point and causes micro explosion of the tooth. This action breaks up the surrounding tissue into small pieces and dissipates them at the same time. As this explosion occurs in water, it is called water-induced preparation ${ }^{[6]}$.
Micro-shear bond strength test was selected as a, bond-assessment method, as done by fong et al., in $2006{ }^{[6]}$ because of its characteristics such as small surface area for bonding, easier preparation of the samples using fewer amounts of material; and also its suitability for testing of adhesion to enamel and dentin.

Van Meerbeek et al., in $2010^{[7]}$ found a good correlation coefficient between the annual failure rates and shear bond strength. This conclusion proves the significance of micro-shear bond strength "in vitro" test and its relevance to clinical outcomes. Micro-shear bond strength is also more reliable, because the stress distribution is more homogenous on the bonding surface of specimens due to their lower dimension, so statistical analysis would be more accurate. 
For enamel etching, several investigations have suggested that high irradiation outputs varying from $2.5 \mathrm{~W}$ to $6 \mathrm{~W}$ can be used (Another study has even used the maximum output power $(6 \mathrm{~W})$, providing increased values of energy density and, as a consequence, a higher efficiency of laser ablation ${ }^{[8]}$. In the literature, there were conflicting reports about the use of lasers for enamel etching. Although some researchers have reported that the mean shear bond strength resulting from laser etching is lower than that from acid etching ${ }^{[7,8]}$., others have reported more favorable results with laser irradiation . In the current study, highest bond strength was achieved in the acid-etched group in comparison to the laser-etched group, this was in agreement with Bulnes et al., in $2013^{[9]}$ and Hoshing et al., in $2014{ }^{[10]}$. This difference may be attributed to the use of higher value of energy density which leads to a more harmful thermal effect on dental hard tissues.

Laser-etched dentin showed the lowest insignificant mean microshear bond strength compared to acid etching treatment. This was in agreement with Dunn et al $2005^{[11]}$ This may be due to the nature of dentin surface after Er,Cr:YSGG laser irradiation $(1.25 \mathrm{~W}, 20 \mathrm{~Hz}, 70 \%$, water $60 \%$ air). Erbium laser was mainly absorbed by water and other hydrated organic components of the tissue.

Time showed an insignificant effect on mean microshear bond strength (MPa) for both acid etched and laser conditioned enamel and dentin. This may be attributed to the short testing period which will not represent ultimate bond strength since it may require longer testing time.

\section{CONCLUSIONS}

Under the limitations of this study the following conclusions were derived:

1. Etching with Er,Cr: YSGG laser impair the micro shear bond strength of resin composite to enamel and does not constitute an alternative to its acid etching.
2. Both Laser and acid etching have a comparable effect on micro shear bond strength of resin composite to dentin.

3. Aging did not hinder the micro shear bond strength of resin composite to lased or acid etched treated substrate.

\section{CLINICAL RECOMMENDATIONS}

Still etch and rinse adhesive system is the recommended technique for bonding to enamel

\section{REFERENCES}

1- Hibst R (2004) Laser for caries removal and cavity preparation: state of the art and future directions. J Oral Laser Appl 2:203-212.

2- Hibst R, Keller U (1989) Experimental studies of the application of the Er:YAG laser on dental hard substances: I. Measurement of the ablation rate. Lasers Surg Med 9:338-344.

3- Türkmen, C., Sazak-Oveçoğlu, H., Günday, M., Güngör, G., Durkan, M., \& Oksüz, M (2010) Shear bond strength of composite bonded with three adhesives to Er,Cr:YSGG laser-prepared enamel. Quintessence International (Berlin, Germany : 1985), 41(6), e119-e124.

4- Chou, J., Chen, C., Ph, D., \& Ding, S (2009) Effect of Er, Cr : YSGG Laser Parameters on Shear Bond Strength and Microstructure of Dentine. Photomedicine And Laser Surgery, 27(3), 481-486.

5- Obeidi, A., Liu, P. R., Ramp, L. C., Beck, P., \& Gutknecht, N (2010) Acid-etch interval and shear bond strength of Er,Cr:YSGG laser-prepared enamel and dentin. Lasers in Medical Science, 25(3), 363-369.

6- Foong, J., Lee, K., Nguyen, C., Tang, G., Austin, D., Ch'ng, C., Thomas, D. L (2006) Comparison of microshear bond strengths of four self-etching bonding systems to enamel using two test methods. Australian Dental Journal, 51(3), 252-257.

7- Van Meerbeek, B., Peumans, M., Poitevin, a, Mine, a, Van Ende, a, Neves, a, \& De Munck, J (2010) Relationship between bond-strength tests and clinical outcomes. Dental Materials: Official Publication of the Academy of Dental Materials, 26(2), e100-21. 
8- Cardoso MV, De Munck J, Coutinho E, Ermis RB, Van Landuyt K, de Carvalho RC, Van Meerbeek B (2008) Influence of Er, Cr: YSGG laser treatment on microtensile bond strength of adhesives to enamel. Oper Dent 33:448-455.

9- Contreras-Bulnes, R., Scougall-Vilchis, R. J., RodríguezVilchis, L. E., Centeno-Pedraza, C., Olea-Mejía, O. F., \& Alcántara-Galena, M. D. C. Z (2013) Evaluation of selfetching adhesive and Er:YAG laser conditioning on the shear bond strength of orthodontic brackets. The Scientific World Journal 10:11-55.
10- Hoshing, U., Patil, S., Medha, A., \& Bandekar, S (2014) Comparison of shear bond strength of composite resin to enamel surface with laser etching versus acid etching: An in vitro evaluation. Journal of Conservative Dentistry, 17(4), 320 .

11- Dunn WJ, Davis JT, Bush AC (2005) Shear bond strength and SEM evaluation of composite bonded to Er:YAG laser-prepared dentin and enamel. 